\title{
MAGDA ZAVALA Y SU TRÍPTICO DE LAS MAREAS: HACIA UN NUEVO ENTENDIMIENTO HUMANO EN TRES POEMAS CLAVES
}

\author{
Jorge Chen Sham
}

\begin{abstract}
RESUMEN
Magda Zavala nos propone el acto de independencia y de toma de conciencia, gracias a los cuales el sujeto poético en Tríptico de las mareas se arriesga a dar ese salto cualitativo del que hablaba Inmanuel Kant para definir la Ilustración como la salida de un estado de minoría de edad. Magda Zavala nos invita a ya no seguir obedeciendo ciegamente a esa retórica hueca de las palabras, a las poses intelectuales a los fariseísmos culturales y personales, como tampoco a mantener la subordinación a sumisiones políticas, religiosas o culturales, sobre todo, en lo que se refiere a las trampas del machismo atávico y nos conduce hacia un nuevo entendimiento entre los sexos y de las relaciones hombre/mujer. En tanto "tríptico", tomaremos un poema clave de cada uno de los tres poemarios para mostrar la pertinencia de esta propuesta poética.

Palabras clave: Magda Zavala, poesía costarricense, feminismo, sujeto femenino.
\end{abstract}

\begin{abstract}
Magda Zavala brings us the act of independence and taking of conscience, thanks to which the poetic subject of Tryptych of the Tides risks herself to give that qualitative jump of which Immanuel Kant spoke in order to define the Illustration as the exit from the state of being in the minority of age. Magda Zavala invites to us no longer to continue blindly obeying the hollow rhetoric of words, the intellectual poses of the cultural and personal Pharisees, to maintain subordination to political, religious or cultural submissions above all, concerning the pitfalls of atavistic masculinity and she drive us towards a new understanding between the sexes and of the male/female relationships. In as much "Tryptych", we will take a key poem from each one of the three book of poems to show the relevance of this poetic proposal.
\end{abstract}

Key words: Magda Zavala, Costa Rican poetry, feminism, female subject.

Magda Zavala reúne, en este Tríptico de las mareas, parte importante de su poesía escrita en los últimos treinta años. Con la amplitud temporal y la distancia biográfica que le proporcionan los hechos, tanto de editar con un criterio de unidad y significación, así como de vislumbrar un itinerario a su propio camino de escritura en tanto aprendizaje, la poeta Magda

Dr. Jorge Chen Sham. Profesor de la Escuela de Filología, Lingüística y Literatura. Universidad de Costa Rica. Correo electrónico: jorgechsh@yahoo.com

Recepción: 27- 10- 2010

Aceptación: 25- 11- 2010 
Zavala se nos manifiesta con una madurez poética y un pulimento reflexivo de su lenguaje que cualquier poeta novel se lo desearía. Y, en ese sentido, se trata de una nueva poeta porque este es su primer libro publicado, aunque algunos de sus poemas hayan circulado sueltos o en antologías; además de que, por años, ha venido escribiendo y guardando hasta que ese momento propicio se presentara. Ha venido la hora de reunirlos; pero ella lo realiza bajo la convicción de que su biografía personal y el camino de aprendizaje que su tríptico encierra es susceptible de comunicarse y de enriquecer, en la lectura, las vivencias de aquellos lectores en los que haga eco y motive su poesía.

De esta manera, Tríptico de las mareas nos somete a un reto lúdico y crítico a la vez; para ello, se vale Zavala de ese juego con la tradición poética anterior y contemporánea, la conciencia de las estrategias de lenguaje y de los mecanismos expresivos, así como también de una utilización ingeniosa y crítica de las figuras y tropos de la poesía. El homenaje a la tradición literaria, así como su juego paródico resaltan, no como mera pose intelectual de quien ejerce como profesora y crítica universitaria, sino como una necesidad existencial de establecer su patrimonio discursivo y sus filiaciones estéticas. En este sentido, lo digo con toda seguridad, Zavala es una de las poetas costarricenses más conscientes del medio que problematiza y de las posibilidades genéricas, sobre todo cuando se trata de utilizar las capacidades expresivas del epigrama y de la elegía por un lado y, por otro, de recursos como el hipérbaton, la anáfora, el paralelismo, la ironía y la antítesis, así como otros juegos del significante y de la tipografía que acerca a Zavala a la poesía más audaz y experimental.

Ello nos conduciría a ese reto crítico que problematiza Zavala cuando nos enfrentamos al espacio privado de la relación de pareja, a los conflictos intersubjetivos del sujeto femenino en la encrucijada de estos tiempos posmodernos en los que las certidumbres y los absolutos han desaparecido, a la toma de posición ética que conduzca a actuaciones políticas y personales sinceras y transparentes. Como portavoz y heredera de la Generación de ALCOA, la que diseñó un escenario social y político más justo y utópico ${ }^{1}$, en Tríptico de las mareas, Magda Zavala nos narra una historia colectiva que conducirá de la efervescencia política y las posibilidades amorosas a la decepción, quiebra de las ilusiones y de los desencantos, hacia la viabilidad de una reconfiguración de las relaciones humanas y la reconstrucción de un espacio solidario para quienes se sienten parte de la Humanidad.

Sin embargo, Zavala no se encierra en posturas críticas que no nos conducirían a nada y apuesta, a pesar de esos sinsabores y decepciones, a rediseñar un nuevo escenario de entendimiento humano y a ilusionarnos de nuevo con nuevos proyectos en los que encuentren, codo a codo, el derecho de la reivindicación de lo femenino, la búsqueda del amor de pareja y la insistencia en un nuevo mundo que debemos heredar a futuras generaciones, en una revolución de "mareas" de oposición. Es como si Magda Zavala dialogara con Michel Foucault, uno de esos pensadores fundamentales en nuestra Posmodernidad cultural, y entablaran aquí un diálogo de ética y llegaran a la misma conclusión, la opción de conciencia y la posibilidad de una revolución en el plano individual se imponen, tal y como Foucault explica cuando Inmanuel Kant en su famoso discurso “QQué es la Ilustración?” se planteaba lo mismo:

¿Y cuál es esta consigna [de la Aufklärung]? Aude saper, "ten el valor, la audacia de saber". Por lo tanto, es necesario considerar que la Aufklärung es a la vez un proceso del que los hombres forman parte colectivamente y un acto de valor que se ha de efectuar personalmente. Ellos son, a la vez, elementos y agentes del mismo proceso. Pueden ser los actores de dicho proceso en la medida en que forman parte de él; y éste se produce en la medida en que deciden ser los actores voluntarios del mismo. (1999: 338) 
Saber escuchar su propia voz y vislumbrar su propio proyecto. He aquí lo que aprende Magda Zavala en esta encrucijada de su existencia, en un acto de una gran independencia, gracias al sujeto poético en Tríptico de las mareas se arriesga a dar ese salto cualitativo del que hablaba Inmanuel Kant para definir la Ilustración como la salida de un estado de minoría de edad. Magda Zavala nos invita a ya no seguir obedeciendo ciegamente a esa retórica hueca de las palabras, a las poses intelectuales a los fariseísmos culturales y personales, como tampoco a mantener la subordinación a sumisiones políticas, religiosas o culturales, sobre todo, en lo que se refiere a las trampas del machismo atávico. Ello hace que la situación comunicativa del tríptico zavaliano esté mediatizado por mecanismos de escritura que se apropian de lo autobiográfico (la toma de conciencia, el proceso de formación del personaje, el principio modelador del caso personal y la experiencia colectiva) y se decante por su arraigo a la realidad vivida por la poeta como si fuera un camino de aprendizaje. La realidad compleja y contradictoria se lee en un proceso de escritura/lectura y Magda Zavala analiza los acontecimientos individuales y colectivos para desentrañar las causas de esas acciones en el tejido de los afectos y de los encuentros del ser humano, en un ritmo y un dinamismo que quiere precisamente rescatar el simbolismo del agua del mar que corre, cuyo movimiento serían las mareas. Este trabajo quiere ser solamente un primer acercamiento de conjunto a este macro-poemario, que se estructura como un tríptico para el lector y, para ello, me centraré en el análisis de un solo poema/clave por libro, para ser consecuente con el tríptico.

El primer libro del Tríptico de las mareas, "Habitante extraño", se presenta bajo la conjunción del sol, de la aurora y del mediodía que iluminan ese camino de aprendizaje a dos. La significación de "Habitante extraño" se concentra en el paradigmático haikú inicial, el cual revela ese tono que marca este libro; se intitula "Desterrado" y dice: "El buen amor deambula a ciegas/ golpeándose contra el azar" (13)². A la luz de lo anterior, queda claro que en "Habitante extraño" estamos ante un exilio. Desde el punto de vista metafórico, ese espacio que se ha perdido se plantea gracias a la prosopopeya: "El buen amor deambula a ciegas/ golpeándose contra el azar" (13); la sinécdoque que encierra subraya la deriva de quien pasea "sin guía determinada [...] sin rumbo fijo" (Cuvardic 2009: 25); es decir, "errante en el trayecto físico de la ciudad y errante en sus reflexiones" (Cuvardic 2009: 27). Por esta razón, la persona que "deambula" podría, como el "flâneur" mirar distanciadamente, mirar hacia la otredad. Así, la relación metafórica que se posibilita conduce a la equivalencia semántica entre ese espacio ya no habitado y la ausencia del amor, que "deambula" sin rumbo, porque ya no puede habitar el corazón de su amante.

El amor es el actor convocado bajo los efluvios de la relación de pareja, ahora metamorfoseada en palestra, encuentro, tálamo, convivio, incógnita o banquete; se trata de un escenario a la vez vital y sentimental en el que coexisten las ilusiones y las vivencias del espacio que se plantea compartido entre ambos amantes; pero ¿hasta cuándo? De ahí el adjetivo "extraño" para designar a ese "tú" amoroso que la voz poética intenta recrear y significar en su dimensión más personal, en esos ámbitos/lugares tales como el paseo, la fruición del erotismo, el mar y la playa, la entrega, la alcoba, el despertar; todos ellos son espacios de ese deseo del otro que no se colma y no llega a saciar completamente, aunque se vive intensa y desaforadamente. Tomemos como ejemplo de ello, el poema "Nuestra alcoba, el mar", en donde la escena que se dibuja retomando el tópico de Ut Pictura Poesis es una "marina": 
Redes, boyas, aparejos, mallas anudadas,

concha nácar, un calamar gigante con ojo estático,

trasmallos, cañas y algún traje húmedo en desuso;

un barco atrapado entre vidrios celestes,

su quilla profunda, su mástil obsesivo [...]. (31)

La ambientación del poema sorprende por la perspectiva vertical que supone la aparición del "barco", después de describir una serie de elementos relacionados con el mar y la navegación. El movimiento hacia el horizonte y la perspectiva nos propulsa hacia el cielo en la sinécdoque "vidrios celestes", para luego ofrecernos una imagen de conjunto cuando se mencionan tanto la "quilla" como el "mástil"; lo aéreo gana en intensidad, cuando nos damos cuenta de que las dos metonimias de "barco" en el verso 5 ("quilla" y "mástil") se califican con unos adjetivos que remiten, desde mi opinión, a una acción humana, apenas esbozada sutilmente en estos dos adjetivos ("profunda" y "obsesivo"), tal y como se develará al final del poema. No se nos olvide que el motivo del barco, de gran prosapia en nuestra cultura occidental, relaciona "la navigation comme symbole de la traversée de la vie terrestre" (Torres 2009: 110), gracias a lo cual la barca se convierte en sinécdoque del ser humano gracias a su relación con el cuerpo. La descripción del cuadro continúa ahora con una referencia explícita a lo humano dentro del paisaje marino:

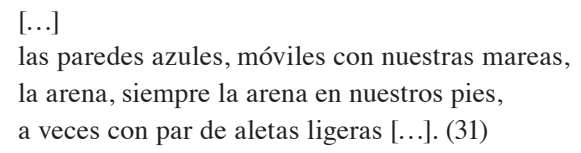

Sorprende la interacción y el movimiento en la imagen de "mareas" y "pies"; se va insinuando muy delicadamente ese ritmo y compás entrelazado de los dos amantes con el que termina el poema, porque la escena marina, de una naturaleza estática, solamente cobra vida con la intromisión/presencia de la pareja de amantes; es más, fijémonos que las "mareas" del verso 9 son provocadas por la interacción humana, no es propia de la naturaleza. El poema termina con la aparición del primer plano y eje axial del cuadro, cuando descubrimos a los amantes "marinos":

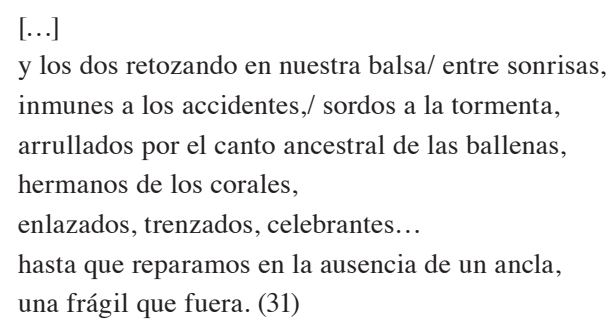

El "barco" inicial ahora se metamorfosea en una "balsa", lo cual le proporciona vulnerabilidad y fragilidad, se acompaña de una acción evidentemente sexual; el dinamismo y el movimiento de los dos amantes acoplados se anuncia en este verbo (retozar) que también explica el tipo de navegación de los dos amantes; la fruición y el goce se desatan para que los amantes se olviden del entorno ni se preocupen de los peligros ("inmunes a los accidentes,/ sordos a las tormentas") que la navegación comporta. Todo el entorno marino exulta; para ello Zavala escoge dos imágenes que dibujan abajo/arriba del fondo marino, pues se trata del dominio/acompañamiento de "corales" y "ballenas", respectivamente, en este momento en que 
la navegación se presenta como controlable en la intensidad de los efluvios amorosos, aunque el mar esté furioso y tormentoso. Se trata de la simbiosis perfecta entre mar en movimiento y fruición de los amantes. Sin embargo, el desenlace inesperado nos plantea una sorpresa y nos remite directamente al símbolo de una navegación que no se puede controlar y puede hacer encallar a los dos amantes. La ausencia del "ancla" salvadora resemantiza el motivo del mar tempestuoso, la seguridad de la navegación (de la relación amorosa) es incierta, sin esta guía o instrumento de seguridad (Balavoine 2009: 80-81). El tono lastimero del verso final, propio de las elegías amorosas en nuestra tradición occidental (Bauzá 2007: 17), intensifica lo sentimental ${ }^{3}$, de esa relación que ha ido a puerto seguro, para retomar el motivo poético empleado.

El segundo libro de Tríptico de las mareas, "Consejas al amigo incierto", es el más audaz e incisivo desde el punto de vista de su propuesta sobre las relaciones de pareja y de las preguntas que se hace la voz lírica en un mundo, que también es "incierto". La incertidumbre nos conduce a un terreno en el que nada es seguro y en el que las interrogantes más bien molestan y son nada tranquilizantes. Para ello Magda Zavala se vale del género epigramático y se conjuga en el epigrama "la sutil agudeza y una agradable ironía" (Fernández Valverde y Ramírez de Verger 1997: 39) con elementos satírico-cómicos y unos desenlaces imprevistos (con "aguijón") que hacen despertar y desestabilizan al lector poco atento ${ }^{4}$. Tomemos como ejemplo de esta actitud contestaria y de molestia el poema "En crisis"; su título ya revela esa posición de desencanto que cala tan hondo en la narrativa de fin de milenio centroamericana, de un pesimismo y de una pérdida de fe (Vargas 2006: 64), pero que aquí se lleva al terreno de las relaciones interpersonales, cuando esa revolución política y de género que se anunciaba como utopía desgastada. Veamos el poema:

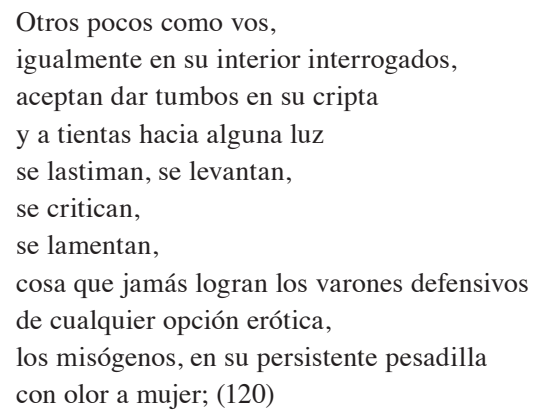

El poema se presenta como un retrato con una ironía muy fina y sarcasmo, cuando de lanzar su dedo acusador se trata. Se establece una comparación que salva las diferencias; la hablante lírica se dirige a su destinatario con el vocativo "vos", al cual intenta separar del resto de sus congéneres. Utilizando el contraste de oscuridad/ luz, que evoca el motivo de la caverna platónica (aquí “cripta”), Zavala subraya la crisis de conciencia (“en su interior interrogados”) para establecer una distinción entre el género masculino, al dividirlos en dos grupos, tal y como enuncia el verso inicial:

$\begin{array}{ll}\text { "Otros pocos" } \quad \text { versus } & \text { "los varones defensivos" } \\ & \text { "los misógenos" }\end{array}$

Toda la construcción sintáctico-morfológica del poema tiende a evidenciar esta oposición: "Otros pocos" versus los más dentro de una relación de cantidad. Al calificar a la mayoría de los hombres con estos dos atributos, la actitud de la hablante lírica conduce 
a cuestionar el machismo y la misoginia. Es más, su estrategia poética se dirige hacia el desenmascaramiento, cuando nos percatamos de que nos propone un desenmascaramiento; veamos con atención los dos atributos utilizados:

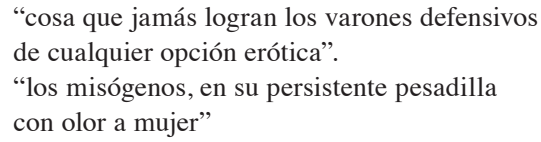

El adverbio temporal "jamás" no solamente denota la negación sino también la aseveración; pero en este caso, desde el punto de vista conceptual, el poema establece una oposición, dentro de un paralelismo antitético:

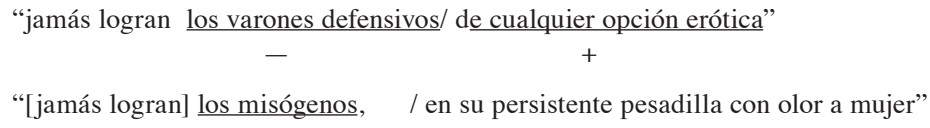

Y estos paralelismos antitéticos resaltan la contradicción: a) más bien estos "varones" se defienden de las opciones y los movimientos que luchan a favor de la libertad y de la expresión sexual, de manera que el poema propugna por la tolerancia, y b) son "misógenos" que odian a las mujeres a pesar de que no pueden vivir sin ellas, de manera que se busca el respeto por la Mujer. Así las cosas, la estrategia de "En crisis" es "dañar la imagen positiva del contrario" (Bolívar 2005: 146), cuyas dos funciones son:

1) Ridiculizar. El objetivo es "convertir al oponente en objeto de burla, hacer que los demás se rían de su persona, acciones o decisiones". (Bolívar 2005: 148)

2) Humillar. El objetivo es "degradar al oponente en su estima personal, profesional”. (Bolívar 2005: 148)

3) Descalificar. El objetivo es "resaltar los rasgos negativos de los oponentes en cuanto a: capacidad intelectual [...], credibilidad, coherencia, responsabilidad, cualidades personales”. (Bolívar 2005: 148)

Así funciona el epigrama, la voz poética es mordaz y elocuente para que termine lanzando su ataque insistiendo en seguir su enumeración:

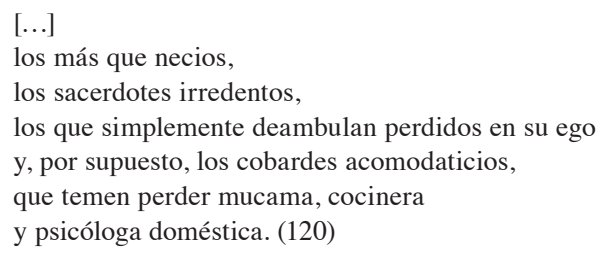

Llama poderosamente ese final sorpresivo en el desenlace del poema. La relación intertextual surge con la conocida sátira de Sor Juana de Inés de la Cruz, en cuyo subtítulo queda explícito el motivo de la crítica de la monja novohispana hacia el género masculino: "Arguye de inconsecuentes el gusto y la censura de los hombres que en las mujeres acusan lo que causan" (Sor Juana de la Cruz 1988: 371); su primera estrofa lanza la primera estocada en lo que se refiere a la inconstancia de los hombres:

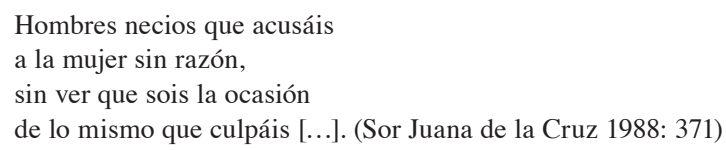


En Sor Juana, la necedad se achaca a lo que el subtítulo del poema llama la inconsecuencia; es decir, si "consecuente" es aquel "que obra conforme a sus teoría" (García Pelayo 1976: 263), en el género masculino habría un desfase entre lo que creen y lo que practican. Esa contradicción es la que cuestiona Zavala en el poema, en primer lugar, cuando señala en las antítesis que veíamos más arriba, la inconsecuencia tanto de "varones defensivos" como de "misógenos" y, segundo, cuando en las aposiciones explicativas especifica esta "necedad" masculina de la siguiente manera, dentro de una enumeración en crescendo que respeta un ritmo tripartito:

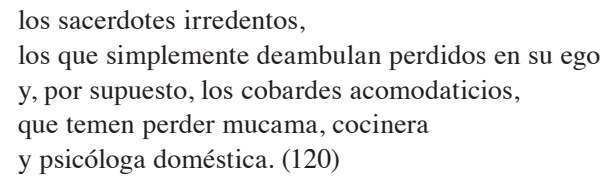

Los califica de: a)"sacerdotes irredentos" (pontifican y acusan a los demás pero que no se pueden salvar); b) "los que simplemente deambulan perdidos en su ego" (egoístas y confundidos en sus ideas); y c) "los cobardes acomodaticios" (inconsecuentes e inmaduros, pues no tienen palabra ni criterio), con el fin de presentarlos como aquellos que se arreglan y actúan conforme al machismo. Y lo son porque siguen perpetuando la escena "doméstica" del discurso falocéntrico, el cual relega a la mujer a servir al hombre. De esta manera, encontramos en "Consejas al amigo incierto" una crítica acre y un reflexión incisiva que devela la necesidad de plantear relaciones más justas y equitativas entre los dos sexos, a partir de ellas se ve las relaciones del yo lírico con su entorno social y político; eso es innegable en un poemario de gran carga ideológica, porque gracias a este cuadro variopinto y diverso de situaciones, "Consejas al amigo incierto" se interesa por hacer una crónica y un testimonio de nuestra sociedad actual. Por lo tanto, a la luz del poema "En crisis", Zavala nos plantea un cuestionamiento a esa ausencia del amado y se hace una diatriba contra todo aquello que impide: a) unas relaciones verdaderamente simétricas entre la pareja, y b) al ser humano vivir con autenticidad y con solidaridad.

El último poemario del libro del Tríptico de las mareas, "Conjunción”, es el más breve de los tres, aunque no por ello menos intenso y propositivo. "Conjunción” intenta resignificar las posibilidades de la utopía en el regreso a los mitos ancestrales y a las historias antiguas vueltas a revisitar. Y el primer lugar que se aborda de nuevo es la construcción de un espacio alternativo y fraterno, con el fin, en segundo lugar, de redescubrir el sentido de las cosas que rodean al ser humano; se trata de "la función anunciadora del proceso emancipador" (1994: 27), tal y como ha visto James Iffland en la poesía centroamericana más radical. Por ejemplo, "Otra Penélope" vuelve sobre el mito de Penélope a través del artificio de la máscara poética, con el fin de actualizar un mito que promueve el sistema patriarcal y la dominancia de la mujer, sojuzgada bajo el arbitrio del hombre y de relaciones asimétricas entre los dos sexos (Chen 2007: 185).

Así, la voz lírica actualiza ese papel de Penélope; pero se hace desde un inconfundible cuestionamiento, pues "se vuelve algo fundamental para la mujer actual, porque de esta manera pone en tela de juicio la veracidad de los mismos" (Vallejos 2000: 135). El poema "Otra Penélope" es un elegía, en la que domina el tono lastimero (Bauzá 2007: 19), propio a la expresión de los sentimientos más genuinos del individuo. En cuanto al mito, Zavala hace que su Penélope desarrolle dos de sus mitemas esenciales: la espera y el telar de la escritura ${ }^{5}$. De esta manera, Penélope escribe en su intimidad y Zavala recurre al diario íntimo, cuando anota 
la voz lírica en el verso introductorio y que sirve de encuadre textual: "Escribió para sí, en sus libretas compañeras" (265). Esas "libretas compañeras", en su soledad, permiten que el sujeto se vuelque sobre sí mismo y escriba sus impresiones y comentarios más personales, ajeno a los ojos exteriores de otras personas; por eso, el diario comparte con la novela epistolar "cette possibilité extraordinaire qu'[ils offrent] de situer le lecteur au lecteur au coeur même d'une conscience qui se découvre en écrivant directement, de manière transparente, dans le tumulte de ses passions" (Calas 1996: 9). Eso es lo que sucede a continuación, cuando esta voz lírica se inmiscuye en lo que, tal vez, no deberíamos leer y nos reproduce un fragmento de este diario íntimo de Penélope, el cual aparece en cursiva:

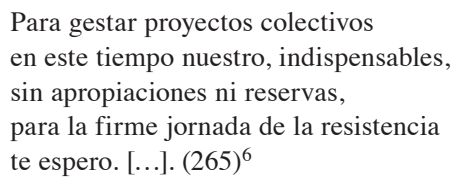

La espera es inédita e implica un nuevo espíritu de entendimiento mutuo; Penélope no espera a su cónyuge siguiendo los parámetros de la esposa tradicional; las ilusiones se mantienen en el cambio posible, lo cual ella denomina como "proyectos colectivos", con sentido prospectivo y realizable si se trabaja en conjunto. La existencia inmediata se describe como "firme jornada de la resistencia", lo cual contrasta con la pasividad de la espera de la Penélope del mito homérico. De manera que no hay transformación posible de las relaciones entre marido/ mujer, si no se produce esta toma de conciencia inicial. Sin embargo, ¿es esto suficiente? Analicemos lo que plantea Julián Marías en relación con las expectativas de una posible realización truncada:

\begin{abstract}
La ilusión experimenta otro cambio. Se acentúa, extrema su tensión, hasta hacerse a la vez deleitosa y penosa; al mismo tiempo surge un elemento de temor. ¿A qué? No, como antes, a que no se cumpla; más bien a que no se cumpla su promesa, a que no responda a la anticipación, a la carga con que se estaba aguardando la realización. Es el temor a que la ilusión quede por debajo de sí misma al hacerse presente, a que resulte una desilusión. (49)
\end{abstract}

Pues bien, este proceso es el que se produce en el resto del poema; la súplica de Penélope despliega el temor y sus dudas:

No vayás a dejarme con mi pañuelo húmedo,
contando uno a uno minutos ingratos
en un reloj de viento. (265)

El mitema de la espera contagia el texto para que la ilusión apasionada de la primera estrofa se transforme, en esta, en dolorosa inseguridad ("mi pañuelo húmedo"), ligada al tiempo que avanza inexorablemente y que expresa la posibilidad de una promesa truncada (“minutos ingratos”). Sin embargo, la resolución de la Penélope zavaliana no se hace esperar; no está dispuesta a continuar con esa esclavitud del tiempo y le expecta en signo de precaución:

\footnotetext{
Y si acaso fuera lejana tu existencia quizás me anime a parirte para otra, más afortunada

porque estarás en su hora. (265)
}

La oración condicional encierra ese obstáculo que los separa ("fuera lejana tu existencia"), mientras que la apódosis, con el adverbio "quizás" subraya al contrario de una conjetura o una posibilidad, su determinación de no esperarlo. La expresión "estar en su hora" 
implica valorar no solo la oportunidad y conveniencia, sino también la puntualidad, a causa de lo cual la Penélope zavaliana no aceptaría más una espera y lo dejaría. Incisiva y mordaz es la forma que selecciona Zavala para trastocar la imagen de la esposa fiel y pasiva, pues ella estaría dispuesta a "a parirte para otra", es decir, en un sentido figurado, desembarazarse de él si fuera el caso. Por lo tanto, en "Otra Penélope" la conjunción de los amantes es solamente posible en un terreno de común entendimiento y de aceptación mutua; por ello, el ámbito de las relaciones interpersonales provoca que, en el proceso emancipatorio y la responsabilidad ética, Magda Zavala nos conduzca a reinterpretar cosmogonías antiguas por un lado y, por otro, a intentar una sonoridad todavía incipiente en otros textos de este poemario. Se trata de una liberación de los cuerpos y del sujeto femenino sí; pero ante todo un aggiornamiento de las conciencias ahí en donde los marasmos de la Posmodernidad nos impiden soñar y desear y nos invita, como en "Otra Penélope", a "proyectos colectivos".

Para terminar, quisiera destacar el nivel del lenguaje y el manejo de la escritura, pues todo el Tríptico de las mareas corresponde a un ejercicio autoconsciente del proceso poético. Magda Zavala empieza a jugar con las tipografías y con las posibilidades de la página; hay rupturas y fragmentarismos que llaman la atención sobre lo visual (Martínez Fernández 1996: 51) y sobre la enunciación lírica. La distribución de los versos y de la tipográfica; otros aspectos gráficos como la aparición de cursivas, mayúsculas, parentésis, cambios de letra, ausencia de puntuación, en algunos casos el comienzo in media res o en otros muchos casos el final trunco; los encabalgamientos, las anáforas o el hipérbaton consentido y buscado ${ }^{7}$; todos estos mecanismos conducen a tres objetivos:

1) Enfatizan esa tensión entre la oralidad y poesía escrita, para que pueda cuestionarse la linealidad de la página y pueda instaurarse la simultaneidad y el movimiento dentro del poema.

2) Plantean rupturas y transformaciones que, para Zavala, deben captarse en el mismo acto de la creación/lectura del poema; así "“e]l poema cesa de ser una sucesión lineal y escapa así a la tiranía tipográfica que nos impone una visión longitudinal del mundo, como si las imágenes y las cosas se presentasen unas detrás de otras y no, según realmente ocurre, en momentos simultáneos y en diferentes zonas de un mismo espacio o en diferentes espacios" (Martínez Fernández 1996: 54).

3) Necesitan un lector conspicuo y atento; solamente un lector con estas características podrá captar la ironía, la burla, la antítesis, la chanza, el humor que se esconden, si el caso viniere, detrás de lo literal y en lo implícito, pues los silencios y los finales sorpresivos o truncos interpelan con mucho mayor emotividad y eficiencia persuasivoretórica.

\section{Notas}

1. Esa misma línea es la que cohesiona el proyecto de su novela Desconciertos en un jardín tropical (1999).

2. Para simplificar el aparato de citas, solamente pondremos el número de página del poemario.

3. Lamentablemente no puedo elaborar más esta idea; pero los reclamos y las quejas que se exponen en muchos de los poemas de este libro permiten relacionarlos con la elegía latina; su modelo sería el poeta Propercio (ca.50-15 A.C.). 
4. Estos desenlaces sorpresivos no son exclusivos del epigrama: Zavala los ensaya desde "Habitante extraño".

5. Véase el artículo de Sandra Gondouin, en donde ella analiza el mito de Penélope en textos contemporáneos centroamericanos.

6. Si no hay indicaciones, las cursivas pertenecen al texto.

7. No se trata de una lista exhaustiva, la cual no tendría aquí sentido. Lo que deseamos subrayar es que, mediante estos recursos, Magda Zavala busca que un lector no complaciente, avezado, activo, transformador, porque lo invita a tomar posición y a involucrarlo en el acto de escritura/lectura del poema.

\section{Bibliografía}

Balavoine, Claudie. 2009. "Au-dessous/ au-dessus de la plaine marine: dichotomie symbolique dans l'imaginaire de l'emblématique espagnole (1581-1640)”. En: Delpech (ed.), 65-97.

Bauzá, Hugo Francisco. 2007. "Prólogo". Propercio. Elegías completas. Madrid: Alianza Editorial.

Bolívar, Adriana. 2005. "La descortesía en la dinámica social y política”. En: Murillo (ed.), $137-164$.

Calas, Frédéric. 1996. Le roman épistolaire. París: Éditions Nathan.

Chen Sham, Jorge. 2000. Nuevos acercamientos a la obra de Rima de Vallbona (Actas del Simposio-homenaje). San José: Universidad de Costa Rica/ University of Saint Thomas.

2007. "La máscara poética mitológica en la poesía nicaragüense escrita por mujeres: Belli, Alegría y Palacios”. Alba de América. 26 (49-50): 185-203.

Cuvardic García, Dorde. 2009. "La reflexión sobre el flâneur y la flanerie en los escritores modernistas latinoamericanos". Káñina. 33 (1): 21-35.

Delpech, François (ed.). 2009. L’imaginaire des espaces acuatiques en Espagne et au Portugal. París: Presses Sorbonne Nouvelle.

Fernández Valverde, Juan y Antonio Ramírez de Verger. 1997. “Introducción general”. Marcial. Epigramas. Madrid: Editorial Gredos.

Foucault, Michel. 1999. “QQué es la Ilustración?”. Estética, ética y hermenéutica. Obras esenciales, Volumen III. Barcelona: Ediciones Paidós Ibérica. 
Gondouin, Sandra. 2010. "Penélope y Ulises en la poesía contemporánea de América Central”. Centroamericana. 18: 31-49.

Iffland, James. 1994. Ensayos sobre la poesía revolucionaria de Centroamérica. San José: EDUCA.

Juana Inés de la Cruz (Sor). 1988. Lírica. Barcelona: Ediciones B.

Marías, Julián. 1990. Breve tratado de la ilusión. (2 ${ }^{\text {da }}$ reimpresión). Madrid: Alianza Editorial.

Martínez Fernández, José Enrique. 1996. El fragmentarismo poético contemporáneo. León: Servicio de Publicaciones de la Universidad.

Murillo Medrano, Jorge (ed.). Actas del II Coloquio Internacional del Programa EDICE "Actos de habla y cortesía en distintas variedades del español: Perspectivas teóricas y metodológicas". Estocolmo/San José: Programa EDICE/ Instituto de investigaciones Lingüísticas.

Torres, Luc. 2009. "Boussole à l'usage des navigateurs du frontispice marin de La Pícara Justina”. En: Delpech (ed.), 99-111.

Vallejos, Mayela. 2000. "El uso de la parodia como elemento desmitificador en 'Penélope en sus bodas de plata".. En: Chen (ed.), 135-146.

Vargas, José Ángel. 2006. La novela contemporánea centroamericana: La obra de Sergio Ramírez Mercado. San José: Ediciones Perro Azul.

Zavala, Magda. 1999. Desconciertos en un jardín tropical. San José: Editorial Guayacán. 2010. Tríptico de las mareas. San José: Editorial Osadía. 
